\title{
COMENTARIO A LA SENTENCIA DEL TRIBUNAL CONSTITUCIONAL 12/2008, DE 29 DE ENERO, SOBRE LA LEY ORGÁNICA PARA LA IGUALDAD EFECTIVA DE MUJERES Y HOMBRES
}

\author{
M ${ }^{a}$ LUZ MARTÍNEZ ALARCÓN \\ Profesora de Derecho Constitucional \\ Universidad de Castilla-La Mancha
}

\author{
SUMARIO \\ I. La discusión de la Disposición Adicio- \\ nal Segunda de la Ley Orgánica para la \\ igualdad efectiva de mujeres y hombres \\ en sede constitucional \\ II. Naturaleza de la medida \\ III. Juicio de constitucionalidad
}

\section{LA DISCUSIÓN DE LA DISPOSICIÓN ADICIONAL SEGUNDA DE LA LEY ORGÁNICA PARA LA IGUALDAD EFECTIVA DE MUJERES Y HOMBRES EN SEDE CONSTITUCIONAL.}

Nuestro legislador, convencido de que la situación de desigualdad de la mujer con respecto al varón presenta todavía hoy múltiples manifestaciones, ha decidido apostar por una estrategia global y transversal para luchar contra todas ellas y conseguir así una igualación eficaz entre los dos géneros aprobando la Ley Orgánica 3/2007, de 22 de marzo, para la igualdad efectiva de mujeres y hombres ${ }^{1}$. Esta norma, por lo que al ámbito representativo se refiere, reserva un cierto porcentaje (cuota) por razón de sexo en el momento de la composición de las candidaturas electorales con el objeto de corregir la

1 Sobre la importancia de la transversalidad como instrumento jurídico para la consecución de la igualdad por razón de género véase $\mathrm{M}^{\mathrm{a}} \mathrm{L}$. BaLAguer, Mujer y Constitución. La construcción jurídica del género, ed. Cátedra, Madrid 2005, págs. 91-104. 
situación de desigualdad de hecho en el acceso al cargo representativo existente entre el colectivo de varones y el colectivo de mujeres.

En concreto, la previsión legal de la cuota electoral en la disposición adicional segunda de la Ley Orgánica para la igualdad efectiva de mujeres y hombres se aplica a todos los procesos electorales, obliga a los órganos competentes para la elaboración de las candidaturas electorales (partidos políticos, coaliciones, federaciones y agrupaciones de electores) a respetar un determinado porcentaje por razón de sexo en el momento de la composición de las mismas "de forma que en el conjunto de la lista los candidatos de cada uno de los sexos supongan como mínimo el cuarenta por ciento ${ }^{2}$, exige que la proporción mínima del cuarenta por ciento se mantenga en cada tramo de cinco puestos (incluso en las listas de suplentes) en los procesos electorales al Congreso, Parlamento europeo, autonómicos y locales ${ }^{3}$, incorpora ciertas excepciones en cuanto establece que el respeto de dichos porcentajes no será exigible en los municipios con un número de residentes igual o inferior a 3.000 habitantes ni en las islas con un número de residentes igual o inferior a 5.000 habitantes $^{4} \mathrm{y}$, finalmente, prevé que el in-

2 Para el caso de las elecciones autonómicas los porcentajes establecidos se presentan como una regla de mínimos ya que se permite que las correspondientes leyes electorales autonómicas establezcan medidas que favorezcan una presencia todavía mayor de las mujeres en las candidaturas de sus respectivos procesos electorales. Por el momento, ésta sería la situación de las Comunidades Autónomas de las Islas Baleares, Castilla-La Mancha, País Vasco y Andalucía. Las previsiones contenidas sobre esta materia en las Leyes electorales vasca y andaluza están pendientes de un recurso de inconstitucionalidad. El art. 23.1 de la Ley 1/1986, de 2 de enero, Electoral de Andalucía (según redacción dada por la Ley 5/2005, de 8 de abril), establece una cuota "de cremallera" al igual que ya hicieran Baleares y Castilla-La Mancha (las candidaturas de estos procesos electorales autonómicos deben integrarse por candidatos de uno y otro sexo ordenados de forma alternativa). Por otro lado, el art. 50.4 de la Ley 5/1990, de Elecciones al Parlamento Vasco (según redacción dada por la disposición final cuarta de la Ley Vasca 4/2005, de 18 de febrero, para la Igualdad de Hombres y Mujeres) presenta una peculiaridad muy importante ya que, atendiendo a su redacción, incluso permitiría la existencia de una lista integrada exclusivamente por mujeres (pero no por hombres), una cuestión ésta sobre la que deberá pronunciarse el Tribunal Constitucional cuando resuelva el recurso de inconstitucionalidad pendiente contra la Ley vasca. En cualquier caso, y aunque la STC 12/2008, de 29 de enero, no se pronuncia sobre ciertas cuestiones de cuota electoral que todavía tiene pendientes (casos andaluz y vasco), lo cierto es que realiza alguna afirmación que nos puede ayudar a prever cuál puede ser su decisión al respecto en el futuro. En efecto, el FJ $8^{\circ}$ de dicha resolución interpreta que el nuevo artículo 44 bis 1 LOREG habilita a las Comunidades Autónomas para dictar normas electorales que eleven la cuota de representación de la mujer en las candidaturas electorales hasta acercarla al cincuenta por ciento (pero no, parece, más allá de ese cincuenta por ciento).

3 Si bien la regla general, relativa a la necesidad de respetar la cuota en cada tramo de cinco puestos, se excepciona en tres supuestos: para las listas cuyo último tramo sea inferior a cinco, para los casos en que el número de puestos a cubrir por una candidatura sea inferior a cinco y cuando las candidaturas al Senado se agrupen en listas. En todo caso, la proporción de mujeres y hombres debe ser lo más cercana posible al equilibrio numérico; J. Sevilla Merino, comentario a la disposición adicional $2^{a}$ de la Ley Orgánica para la igualdad efectiva de mujeres y hombres, por la que se modifica la Ley Orgánica del Régimen Electoral General, Comentarios a la Ley de Igualdad, director José Ignacio García Ninet, coordinadora Amparo Garrigues Jiménez, CISS, Valencia 2007, pág. 588.

4 Aunque se introduce un periodo transitorio en virtud del cual lo previsto en el artículo 44 bis sólo será aplicable en los municipios con un número de residentes superior a 5.000 habitan- 
cumplimiento de la cuota electoral legal provoca el rechazo de la candidatura correspondiente por parte de la Administración electoral impidiendo así que las formaciones políticas incumplidoras puedan participar en la contienda electoral.

La constitucionalidad de esta medida ha sido definitivamente respaldada - con un voto particular en contra 5 - por la sentencia del Tribunal Constitucional 12/2008, de 29 de enero, de la que ha sido ponente la Magistrada dña. Elisa Pérez Vega. Esta decisión resuelve la cuestión de inconstitucionalidad núm. 4069-2007, promovida por el Juzgado de lo Contencioso-Administrativo núm. 1 de Santa Cruz de Tenerife, en relación con el artículo 44 bis de la Ley Orgánica 5/1985, de 19 de junio, del Régimen Electoral General, introducido por la disposición adicional segunda de la Ley Orgánica 3/2007, de 22 de marzo, para la igualdad efectiva de mujeres y hombres ${ }^{6}$, y el recurso de inconstitucionalidad núm. 5653-2007, acumulado a la anterior, interpuesto por más de cincuenta Diputados del Grupo Parlamentario Popular del Congreso de los Diputados contra la disposición adicional segunda de la Ley Orgánica 3/2007, de 22 de marzo. Básicamente, y tal y como señala el Tribunal Constitucional, tanto el Auto del Juzgado de lo Contencioso-Administrativo núm. 1 de Santa Cruz de Tenerife por el que se plantea la cuestión de inconstitucionalidad, como el escrito de demanda del recurso de inconstitucionalidad formulado por los Diputados del Grupo Parlamentario Popular del Congreso de los Diputados, efectúan los mismos reproches jurídico-constitucionales a la disposición adicional segunda de la Ley Orgánica para la igualdad efectiva de mujeres y hombres: la vulneración de los artículos 14 y 23 y 6 en relación con el 22 de la Constitución. A ellos se añade, en el recurso de inconstitucionalidad, la posible vulneración de los artículos 16.1, 20.1.a) y 68.5 del mismo texto normativo.

tes en todas las convocatorias municipales que se produzcan antes de 2011 (aplicándose a partir del 1 de enero de ese año la cifra de 3.000 habitantes que será la definitiva). Este modelo de implantación progresiva de los porcentajes fue presentado en su momento como un elemento determinante para la validación constitucional de una norma que estableciera medidas como la que estamos analizando; M $\mathrm{M}^{\mathrm{a}}$ L. BALAGUER, Mujer y Constitución. La construcción jurídica del..., ob. cit., págs. 143-144.

5 Voto particular que formula el Magistrado Excmo. Sr. D. Jorge Rodríguez-Zapata Pérez a la sentencia del Pleno sobre la Ley Orgánica 3/2007, de 22 de marzo, para la igualdad efectiva de mujeres y hombres.

6 La cuestión se planteó en el marco de las elecciones municipales y autonómicas que se celebraron en España en el año 2007. Una formación política de ámbito nacional presentó una lista integrada exclusivamente por mujeres en el municipio tinerfeño de Garachico. La decisión de la Junta Electoral correspondiente de inadmitir la lista fue recurrida ante el Juzgado de lo Contencioso-Administrativo que decidió plantear cuestión de inconstitucionalidad contra la disposición adicional segunda de la Ley Orgánica para la igualdad efectiva de mujeres y hombres a pesar de que la parte afectada pidió el desistimiento en el planteamiento de la cuestión de inconstitucionalidad si la decisión del Tribunal Constitucional, como era previsible, no podía llegar en tiempo. Finalmente la intervención del Tribunal Constitucional a través de la cuestión de inconstitucionalidad impidió resolver a tiempo el conflicto; véase, sobre este caso concreto, R. CABALLERO SÁNCHEZ, "La integración del principio de igualdad en las distintas políticas públicas sectoriales", Comentario a la Ley Orgánica 3/2007, de 22 de marzo, para la igualdad efectiva de mujeres y bombres, ed. Thomson-Cívitas, Pamplona 2007, págs. 269-270. 


\section{LA NATURALEZA DE LA MEDIDA DISPUESTA EN LA DISPOSICIÓN ADICIONAL SEGUNDA DE LA LEY ORGÁNICA PARA LA IGUALDAD EFECTIVA DE MUJERES Y HOMBRES.}

La sentencia del Tribunal Constitucional 12/2008, de 29 de enero, después de indicar los preceptos constitucionales que invocan los recurrentes y de afirmar que los textos internacionales y comunitarios no pueden funcionar como parámetros para enjuiciar la constitucionalidad de las normas con rango legal, dedica su fundamento jurídico tercero a definir la naturaleza de la medida prevista en la disposición adicional segunda de la Ley Orgánica para la igualdad efectiva de mujeres y hombres.

En concreto, el Tribunal Constitucional niega que la medida discutida sea una forma de discriminación inversa o compensatoria (como sabemos, un subtipo de la acción positiva) ${ }^{7}$. Para el Alto Tribunal, el precepto discutido prevé una "fórmula de equilibrio de sexos" que, además, tampoco es estrictamente paritaria porque no obliga a respetar unos porcentajes que garanticen una presencia similar de mujeres y hombres en la composición de las candidaturas electorales conforme a una reserva del cincuenta por ciento (recordemos que el precepto establece que ni el colectivo de mujeres ni el colectivo de varones podrán integrar las candidaturas electorales en una proporción, bien inferior al 40\%, bien superior al 60\%). Esta definición de la medida discutida como "fórmula de equilibrio de sexos" y, en definitiva, su negación como medida de discriminación inversa, se apoya básicamente en su configuración bidireccional, conforme a la cual se asegura que los porcentajes mínimos y máximos establecidos resulten aplicables por igual a uno y otro sexo sin introducir, por tanto, un tratamiento peyorativo para ninguno de ellos; es decir, sin favorecer a un sexo sobre el otro ${ }^{8}$.

7 Sobre los diferentes tipos de tratamientos normativos diferenciados pueden consultarse $\mathrm{M}^{\mathrm{a}}$ A. MarTín VIDA, Fundamento y límites constitucionales de las medidas de acción positiva, ed. Cívitas, Madrid 2003, págs. 35-53; y los siguientes textos de D. GIMÉNEz GlucK: Una manifestación polémica del principio de igualdad: Acciones positivas moderadas y medidas de discriminación inversa, ed. Tirant lo Blanch, Valencia 1999; y "El control de constitucionalidad de las cuotas basadas en la clase social", Cuadernos Constitucionales de la Cátedra Fadrique Furió i Ceriol, núms. 30-31, 2000.

8 Este mismo argumento se reitera en los fundamentos jurídicos $5^{\circ}$ y $9^{\circ}$ de la STC $12 / 2008$, de 29 de enero. Por otro lado, la profesora Biglino Campos ya señaló en su momento que para sostener la constitucionalidad de las candidaturas paritarias basta con constatar que las leyes que las prevén no establecen ninguna diferencia normativa de trato entre hombres y mujeres; P. BIGLINO CAMPOS, "Acerca de la constitucionalidad de las leyes electorales paritarias", en $\mathrm{M}^{\mathrm{a}} \mathrm{L}$. BALAguer Callejón (ed.), XXV Aniversario de la Constitución española: Propuestas de reformas, Diputación Provincial de Málaga, Málaga 2004, págs. 363 y ss.; siguiendo a Biglino Campos en este punto véase O. SÁnCHEz MuÑoz, La igualdad de oportunidades en las competiciones electorales, CEPC, Madrid 2007, págs. 152-153. Sosteniendo, igualmente, que una formulación neutra de este tipo de medidas supera los problemas planteados en torno a las cuotas véase C. Zoco ZABALA, Probibición de distinciones por razón de sexo. Derecho comunitario, nacional y autonómico, ed. Thomson-Aranzadi, Pamplona 2008, pág. 112; Ma A. Castro Argüelles y D. Álvarez Alonso, La 
En mi opinión, sin embargo, la formulación aparentemente neutra (abstracta) de la medida no puede esconder su verdadera finalidad que no es otra que la de compensar (como pretenden las acciones positivas - affirmative actions - y, más allá, las denominadas medidas de discriminación inversa — reverse discrimination -) la situación de desigualdad existente entre hombres y mujeres en el acceso a los cargos representativos, una finalidad ésta que, por otra parte, se desprende del propio texto de la sentencia del Tribunal Constitucional que analizo. No olvidemos que este mismo Tribunal apoya su argumentación en el artículo 9.2 del texto constitucional, el cual recoge un mandato para que el poder público promueva las condiciones que garanticen la igualdad efectiva y real de los individuos y de los colectivos sociales en los que éstos se integran?.

Parece por tanto, asumiendo un punto de vista sustancial que atiende a la finalidad compensatoria de la medida y no a su configuración formal, que la reserva de ciertos porcentajes por razón de sexo en el ámbito de las candidaturas electorales que efectúa la Ley Orgánica para la igualdad efectiva de mujeres y hombres está mucho más cerca de una medida de reverse discrimination que de cualquier otra cosa porque, en efecto, creo que es indiscutible que esta previsión, en el contexto actual de desigualdad de las relaciones hombre-mujer, que se traduce en una menor probabilidad objetiva de la mujer para alcanzar ciertos puestos ${ }^{10}$, genera una lesión inmediata en los intereses de terceros - los varones- en el proceso de selección política ${ }^{11}$. En de-

igualdad efectiva de mujeres y hombres. A partir de la Ley Orgánica 3/2007, de 22 de marzo, ed. Thomson-Cívitas, Madrid 2007, págs. 102-103.

9 FF.JJ. $2^{\circ}$ y $5^{\circ}$ de la STC 12/2008, de 29 de enero. Más aún, el Tribunal Constitucional aprovecha para resaltar la diferencia existente entre el artículo 9.2 de la Constitución — por la amplitud de su contenido- y los preceptos equivalentes sobre esta materia de las Constituciones francesa e italiana antes de su reforma.

10 Afirmando que la probabilidad objetiva de la mujer para alcanzar ciertos puestos es menor que la de los hombres y que, por tanto, la cuota no beneficia a las mujeres por el simple hecho de serlo, sino por la situación de desventaja del colectivo social al que pertenecen, véase $\mathrm{F}$. Aguiar, "A favor de las cuotas femeninas", Claves de Razón Práctica, núm. 116, octubre 2001, pág. 29. La menor probabilidad de la mujer frente al varón para alcanzar ciertos puestos —entre ellos, los representativos - se deriva, por una parte, de las cargas que aparecen vinculadas de forma directa al embarazo y al nacimiento pero, por otra y fundamentalmente, de la todavía ausencia de una redistribución equitativa de las cargas propias del trabajo doméstico y de la gestión de las situaciones de dependencia (niños, mayores) que habría permitido situar a ambos colectivos en la misma posición de partida sin reducir, a diferencia de lo que sucede actualmente, las oportunidades de la mujer en su vida laboral y más allá en su vida política.

$11 \mathrm{El}$ incremento de mujeres en posiciones de poder dentro de los partidos es un avance importante, si bien hay que tener en cuenta que, en estos casos, una vez aprobada la cuota femenina, los partidos pueden aumentar también el número de puestos decisorios a fin de acomodar a la nuevas mujeres sin tener que prescindir de los hombres que ya desempeñaban cargos de responsabilidad. La aplicación de las cuotas electorales es más complicada ya que, salvo que un partido espere obtener una notable mejora en sus resultados electorales pasados, lo cierto es que la cuota femenina implica, en la práctica, un descabezamiento de quienes ya disfrutaban de dichos cargos; J. JONSON Y C. VALIENTE FERNÁNDEZ, "El movimiento a favor de la democracia paritaria en Francia y España", Revista Española de Ciencia Política, núm. 5, octubre 2001, pág. 103. Afir- 
finitiva, el establecimiento legal de cuotas o porcentajes electorales pretende compensar la situación de desigualdad por razón de sexo existente en el ámbito representativo y provoca una limitación en la disposición de un bien social escaso - el cargo de representación política - para aquellos que no forman parte del grupo infrarrepresentado (los varones).

Por otra parte, la conclusión sobre la naturaleza jurídica de la medida no resulta irrelevante ya que condiciona el análisis de constitucionalidad de la misma, sobre todo la cuestión relativa a su vigencia (definitiva o provisional). Así, la consideración de la medida como "fórmula de equilibrio de sexos", bidireccional y por tanto neutral en su formulación (aunque no en su finalidad), induce a pensar que la norma que establece los porcentajes tiene vocación de permanencia en el tiempo ${ }^{12}$, una idea ésta que, por lo demás, resulta congruente con aquellas tesis - discutibles - sobre la teoría de la representación política que, reconociendo la existencia de intereses de género, sostienen que los hombres no resultan intercambiables con las mujeres durante el proceso de representación política y, consiguientemente, presentan la cuota electoral (que se propone generalmente como paritaria atendiendo a los porcentajes similares de hombres y mujeres existentes en la sociedad) como una medida no provisional, o como ya se ha dicho, con vocación de permanencia en el tiempo ${ }^{13}$.

Es cierto, en cualquier caso, que el Tribunal Constitucional, aún considerando que la medida consiste en una "fórmula de equilibrio de sexos", no hace referencia a la cuestión relativa a su vigencia — temporal o definitiva-. Es más, un análisis detenido de la sentencia permite encontrar pronunciamientos en su seno que pueden conducir a realizar diferentes conjeturas.

Así por ejemplo, podríamos concluir que el Alto Tribunal está pensando en una medida provisional si atendemos al recurso sistemático que realiza al principio de igualdad sustancial del artículo 9.2 de la Constitución ${ }^{14}$, en virtud del cual la justificación de la medida es posible sólo en tanto se mantenga la situación de desigualdad sustancial de hecho que justificó en su día su existencia.

Frente a ello, encontramos también en la sentencia pronunciamientos que nos llevan a pensar que el Alto Tribunal defendería, llegado el caso, la permanencia de la medida. Me refiero, sobre todo, a las afirmaciones vertidas

mando, igualmente, que las cuotas electorales desplazan a candidatos que tradicionalmente habían sido varones véase $\mathrm{M}^{\mathrm{a}} \mathrm{A}$. MARTín VIDA, Fundamento y limites constitucionales de las medidas de acción..., ob. cit., pág. 212.

12 Véase en este sentido F. DefFenu, "La parità tra i sessi nella legislazione electorales di alcuni paesi europei", Diritto Pubblico, 7, 2001, págs. 642-643.

13 Una reciente construcción de esta posición en el ámbito de la doctrina constitucional española puede encontrarse en B. RuIz RoDrígueZ y R. RuIZ MARín, "De paridad, igualdad y representación en el Estado democrático", Revista Española de Derecho Constitucional, núm. 81, 2007, págs. 137-139. Recientemente he criticado esta tesis sobre la representación política en materia de género en Ma L. Martínez Alarcón, "La Ley Orgánica para la igualdad efectiva de mujeres y hombres y la sentencia del Tribunal Constitucional 12/2008, de 29 de enero", Revista de Estudios Políticos (en prensa).

14 Véase, en especial, el FJ $4^{\circ}$ de la resolución. 
en el $\mathrm{FJ} 7^{\circ}$ con ocasión del análisis que realiza de la imposición de los porcentajes a las agrupaciones de electores. En este momento, el Tribunal señala que la "fórmula de equilibrio de sexos" pretende conseguir que "la igualdad efectivamente existente en cuanto a la división de la sociedad con arreglo al sexo no se desvirtúe en los órganos de representación política con la presencia abrumadoramente mayoritaria de uno de ellos". Para el Tribunal, exigir una composición equilibrada por razón de sexo en los órganos de representación política, consecuente a su vez con la distinción de dos grupos sociales por razón de sexo, es perfectamente constitucional "pues se entiende que ese equilibrio es determinante para la definición del contenido de las normas y actos que hayan de emanar de aquellos órganos" ${ }^{15}$ (en concreto, de su contenido en materia de igualdad hombre-mujer). "Exigir a quien quiera ejercer una función representativa y de imperio sobre sus conciudadanos que concurra a las elecciones en un colectivo de composición equilibrada en razón del sexo es garantizar que, sea cual sea su programa político, compartirá con todos los representantes una representación integradora de ambos sexos que es irrenunciable para el gobierno de una sociedad que así, necesariamente, está compuesta". Parece que, al menos, el Tribunal Constitucional está defendiendo la existencia de un interés de género (la consecución de la igualdad hombre-mujer) y que éste sólo se puede incorporar al debate provocando las consecuentes actuaciones por parte de los órganos representativos cuando éstos se integran por mujeres y hombres de una forma equilibrada.

Ahora bien, si se califica la medida como lo que realmente creo que es, una medida de discriminación inversa (eso sí, con una formulación aparentemente neutra), se puede concluir que su vigencia sólo es posible en tanto en cuanto se mantenga la diferencia sustancial de hecho que justificó en su día su existencia ${ }^{16}$. Desde este punto de vista se han formulado propuestas en la doctrina para que el legislador introduzca medidas de revisión o evaluación periódica de los porcentajes establecidos que deberán reducirse cuando haya disminuido la tasa de infrarrepresentación del sexo femenino como consecuencia de la superación de la situación de desigualdad sustancial de hecho previa o, sencillamente, que deberán suprimirse cuando dicha tasa de infrarrepresentación haya desaparecido o ya no responda a una situación social de discriminación real (podríamos pensar, por ejemplo, en ciertos colectivos

15 La cursiva es nuestra.

16 «Una vez que el cambio de reglas del sistema consiga asentar la presencia más o menos paritaria de mujeres y hombres en los puestos de representación política se debería renunciar a esas muletas y confiar en la madurez de la sociedad para articular procedimientos de elección política, convirtiendo el sexo en un aspecto irrelevante de los candidatos"; CABALLERO SÁNCHEZ, "La integración del principio de igualdad en las distintas políticas públicas...", ob. cit., págs. 266-276. Es más, en líneas generales se espera que el Tribunal Constitucional proteja cada vez más la igualdad formal por entender que la realidad social entre hombres y mujeres es cada vez menos desigualitaria; C. Zoco Zabala, Prohibición de distinciones por razón de sexo. Derecho comunitario, nacional y..., ob. cit., pág. 126. 
que renuncien libremente a participar en la vida política del país como consecuencia, sobre todo, de su decepción frente a su funcionamiento) ${ }^{17}$. No ha sido ésta, en cualquier caso, la opción seguida por el legislador de la Ley Orgánica para la igualdad efectiva de mujeres y hombres. Su disposición adicional segunda no prevé ningún plazo de revisión o evaluación de la medida, aunque ello no impide que podamos imaginar una situación en la que un órgano judicial plantee el problema de constitucionalidad de la norma ante el Tribunal Constitucional cuando haya discurrido un plazo de tiempo considerable desde su aprobación y entienda que se ha producido un cambio sustancial de las relaciones hombre-mujer en España que habría conducido a la equiparación de su realidad vital en el ámbito representativo ${ }^{18}$ (sobre todo, gracias a una redistribución equitativa de las cargas propias del trabajo doméstico y de las derivadas por la atención a las situaciones de dependencia hijos, mayores - que habría permitido situar a ambos en la misma posición de partida para conseguir objetivos profesionales y/o políticos). Pero, no obstante ello, la consideración de la medida por el Tribunal Constitucional como una "fórmula de equilibro de sexos" me lleva a intuir que la probabilidad de que el Tribunal concluya, planteado el problema, que la Ley fue constitucional en el momento de su aprobación y durante cierto tiempo pero que la desigualdad sustancial de hecho que justificó en su día su existencia ha desaparecido y que, por tanto, su permanencia ya no resulta justificada, es ciertamente muy baja.

\section{EL JUICIO DE CONSTITUCIONALIDAD SOBRE LA MEDIDA DISPUESTA EN LA DISPOSICIÓN ADICIONAL SEGUNDA DE LA LEY ORGÁNICA PARA LA IGUALDAD EFECTIVA DE MUJERES Y HOMBRES.}

\section{III.1. LA AUSENCIA DE RAZONABILIDAD EN SU INSTRUMENTACIÓN.}

La sentencia del Tribunal Constitucional 12/2008, de 29 de enero, niega que la medida afecte al derecho de sufragio activo del artículo 23.1 de la

17 Véase, al respecto, O. SAlazar Benítez, "Las cuotas femeninas en cuanto exigencia de la igualdad en el acceso a los cargos públicos representativos", Revista de Derecho Político, núms. 48-49, 2000, págs. 448-449; C. Zoco Zabala, Probibición de distinciones por razón de sexo. Derecho comunitario, nacional y..., ob. cit., especialmente págs. 17-22 y 33-36. Esta última autora señala que la previsión de plazos de evaluación de los resultados conseguidos con la medida para proceder, en su caso, a su revisión (su modificación o incluso su supresión) sería un instrumento adecuado para evitar el uso de otros mecanismos de protección de la igualdad (como la cuestión o el amparo) que permitiría cohonestar los principios de igualdad material y de igualdad formal evitando que una norma que originariamente fue constitucional pudiera devenir inconstitucional con el paso del tiempo.

18 Pienso en futuras cuestiones de inconstitucionalidad sobre la medida que se pudieran plantear durante el desarrollo de futuros procesos electorales por considerar que la situación que justificó en su día su existencia ya ha sido superada. 
Constitución ${ }^{19}$ o al derecho de sufragio pasivo del artículo 23.2 del mismo texto normativo ${ }^{20}$, y reconoce, en su fundamento jurídico cuarto, que la primera y principal cuestión consiste en discernir si el legislador orgánico puede reordenar o reorganizar el derecho de partidos con una medida como la recogida en la disposición adicional segunda de la Ley Orgánica para la igualdad efectiva de mujeres y hombres (desde este punto de vista, el Tribunal afirma que el problema constitucional de fondo se plantea sobre todo en el ámbito de los artículos 6 y 9.2 de la Constitución, con conexiones inmediatas con los artículos 22 y 16 del mismo texto normativo).

El intérprete supremo de la Constitución comienza, prácticamente, adelantando su juicio favorable - muy discutible por la razón que más adelante

19 El Tribunal Constitucional afirma que no es posible desprender del art. 23.1 CE un derecho subjetivo de los ciudadanos a una concreta composición de las listas electorales. Nadie puede pretender ser titular del derecho fundamental a que las formaciones políticas enumeradas en el 44 LOREG presenten a terceras personas como candidatos. El sufragio activo se ejerce mediante la elección (que, como sabemos, debe presentar unas características determinadas) sin que forme parte de ese derecho la facultad de otorgar la condición de candidatos a quien no fue propuesto como tal por los sujetos legitimados para ello.

20 La sentencia pone de manifiesto que, aunque la distinta naturaleza existente entre los partidos y las agrupaciones de electores los diferencia desde un punto de vista conceptual, estructural y organizativo, lo determinante es que ninguno de los dos son titulares del derecho de sufragio pasivo. Los miembros de una agrupación de electores no ejercen el derecho de sufragio pasivo, como tampoco lo ejercen los miembros de los órganos de los partidos políticos competentes al efecto. Unos y otros sólo ejercen tal derecho si además de promover una candidatura se integran en ella. Esta medida no altera por tanto la correlación entre la voluntad que el cuerpo electoral manifiesta en el proceso electoral y los candidatos que han obtenido la confianza de los electores. En este sentido, la STC 12/2008, de 29 de enero, considera que el artículo 23.2 CE sólo resultaría vulnerado si la medida se aplicara en la fase de proclamación de candidatos electos (operando a partir de los resultados electorales). En mi opinión, las cuotas electorales legales no afectan al contenido del derecho de sufragio pasivo del art. 23.2 CE que ha sido definido por el Tribunal Constitucional como la garantía de "que accedan al cargo público aquellos candidatos que los electores hayan elegido como sus representantes, satisfaciéndose, por tanto, dicho derecho, siempre que se mantenga la debida correlación entre la voluntad del cuerpo electoral y la proclamación de candidatos" (SSTC 185/1999, de 11 de octubre; 154/2003, de 17 de julio; y esta última 12/2008, de 29 de enero). La cuota electoral legal de la disposición adicional segunda que estoy analizando es una medida que se utiliza en el momento de la confección de las listas de candidatos, una actividad preparatoria precisa para la obtención de la condición de candidato pero que tiene lugar con anterioridad a su proclamación y cuando, por consiguiente y según la jurisprudencia del Tribunal Constitucional, todavía no se puede hablar de la titularidad del derecho fundamental de sufragio pasivo (SSTC 78/1987, de 26 de mayo; 36/1990, de 1 de marzo; 30/1993, de 25 de enero). Sobre la falta de incidencia de las cuotas electorales en el derecho de sufragio pasivo véase, igualmente, J. Sevilla Moreno, Mujeres y ciudadanía: la democracia paritaria, Institut Universitary d'Estudis de la Dona, Universitat de València, València 2004, pág. 88; $\mathrm{M}^{\mathrm{a}}$ A. MARTín VIDA, Fundamentos y límites constitucionales de las medidas de acción..., ob. cit., pág. 216; M. MarTínez Sospedra, "La sombra de Agamenón. Sobre la constitucionalidad del establecimiento de la cuota por razón de sexo en las listas electorales", Cuadernos Constitucionales de la Cátedra Fadrique Furió Ceriol, núms. 30/31, invierno-primavera 2000, págs. 121-123; A. RuIZ Miguel, "Paridad electoral y cuotas femeninas", Aequalitas. Revista Juridica de Igualdad de oportunidades entre mujeres y hombres, Universidad de Zaragoza, núm. 1, mayo 1999, pág. 51; O. SALAZAR BENÍTEZ, El candidato en el actual sistema de democracia representativa, ed. Comares, Granada 1999, págs. 103-104. 
explicaré- sobre la constitucionalidad de la medida. Sólo a continuación expone los argumentos jurídico-constitucionales que justifican su decisión al respecto $^{21}$.

Empieza poniendo de manifiesto, el Alto Tribunal, que la igualdad material recogida en el artículo 9.2 de la Constitución obliga a los poderes públicos - entre ellos, al legislativo- a promover las condiciones para que la igualdad de los individuos y los grupos en los que éstos se integran sea real y efectiva, entre otras realidades, también en el ámbito representativo ${ }^{22}$, aunque, evidentemente, la promoción de la igualdad material en dicho ámbito puede producirse a través de diferentes medidas cuya constitucionalidad, en su caso, debe ser enjuiciada por el propio Tribunal. Y es cierto que la nueva limitación introducida por la disposición adicional segunda de la Ley Orgánica para la igualdad efectiva de mujeres y hombres a la capacidad de presentación de candidaturas no es la única (así, por ejemplo, se pueden mencionar las condiciones referidas a la elegibilidad de los candidatos, a la residencia en algunos supuestos, o incluso a que tales candidaturas se deban incluir en listas cerradas y bloqueadas), pero lo que es mucho más discutible es que la medida se pueda justificar desde un punto de vista constitucional.

Nada puedo objetar a la afirmación que realiza el Alto Tribunal de que la constricción de la libertad de los sujetos legitimados para presentar candidaturas recogida en el nuevo artículo 44 bis de la Ley Orgánica del Régimen Electoral General resulta legítima, ya que su finalidad (la consecución de la igualdad efectiva o material en el terreno de la participación política y, más específicamente, en el acceso al cargo representativo, que se apoya en la constatación de la existencia de supuestos de hecho sustancialmente diferentes en dicho ámbito ${ }^{23}$ ) resulta lícita desde el punto de vista constitucional (arts.

21 La sensación del lector con este tipo de exposición (en la que se adelanta el juicio y se justifica después, además en este caso con argumentos en mi opinión un tanto desordenados y parcos) es la de que el Tribunal Constitucional ha adoptado primero la decisión, y sólo posteriormente se ha ocupado de revestir dicha decisión de las razones jurídico-constitucionales que pudieran servir a su justificación. Esta impresión es con toda seguridad equivocada pues, en efecto, parece difícil dudar de la existencia de un debate jurídico-constitucional sobre la medida en el seno del Pleno del Tribunal Constitucional (sobre todo teniendo en cuenta la existencia del voto particular). Sin embargo, también es cierto que esta forma de presentar la cuestión no resulta precisamente estética, máxime si tenemos en cuenta la relevancia de un órgano como el Tribunal Constitucional (máximo intérprete de la Constitución) y el debate — siempre abierto— sobre su compatibilidad con el principio democrático. La forma que adopte la argumentación es por tanto muy relevante por lo que puede tener de incidencia en la legitimidad de ejercicio de la institución y su consiguiente credibilidad.

22 En esta materia toma como referencia la jurisprudencia previa del propio órgano, en especial, la STC 216/1991, de 14 de noviembre.

23 La implementación de un instrumento de promoción de la igualdad sustancial sólo puede aparecer justificada en la medida en que pretende responder a una situación de desigualdad sustancial de hecho presente (no pasada), aunque, naturalmente, la desigualdad social que persiste en el presente haya sido fruto de una situación de discriminación histórica de la mujer frente al varón. En este mismo sentido C. Zoco ZABALA, Probibición de distinciones por razón de sexo. Derecho comunitario, nacional y..., ob. cit., especialmente págs. 38-40; M ${ }^{\mathrm{a}}$ A. MARTín VIDA, Fundamentos y límites constitucionales de las medidas de acción..., ob. cit., págs. 147-148; F. REY 
9.2 y 14 CE). Una conclusión diferente sostengo, sin embargo, en cuanto a la razonabilidad de su instrumentación, que requiere atender a los efectos de la medida considerada ${ }^{24}$.

En efecto, para el Tribunal, la medida debe aparecer razonablemente instrumentada y en este caso considera que así ha sido: la considera proporcionada porque se limita a exigir una composición equilibrada con un mínimo del cuarenta por ciento de cada uno de los sexos que no parece excesivo sin imponer, por otra parte, orden alguno ${ }^{25}$, y porque, además, se contemplan excepciones en el caso de poblaciones pequeñas que pueden facilitar su aplicación $^{26}$. Añade, además, que la medida también respeta las exigencias cons-

MarTínez, en "La discriminación positiva de mujeres. Comentario a propósito de la Sentencia del Tribunal de Justicia de la Comunidad de 17 de octubre de 1995, asunto Kalanke)", Revista Española de Derecho Constitucional, núm. 47, mayo-agosto 1996, pág. 330, y en "El derecho fundamental a no ser discriminado por razón de sexo", Cuadernos de Derecho Judicial, III-2004, pág. 91; U. MAIDOwsKI, Umgekehrte Diskriminierung. Quotenregelungen zur Frauenförderung im öffentlichen Dienst und in den politischen Parteien, Duncker\&Humblot, Berlin 1989, págs. 128-129; K. M. Sullivan, "Sins of Discrimination: Term's affirmative action cases", Harvard Law Review, núm. 100, 1986, pág. 78 y ss. Muchos son, por otra parte, los estudios que — con referencia a datos estadísticos extraídos de diversas fuentes - han mostrado la persistencia de la situación de desigualdad de la mujer frente al varón en el ámbito representativo. Un ejemplo de ellos podría ser el de la profesora A. Elvira Perales, "La participación política de la mujer", El tratamiento de género en el ordenamiento español, coord. Alberto Palomar Olmeda, ed. Tirant lo Blanch, Valencia 2005, págs. 413-462.

$24 \mathrm{La}$ justificación constitucional de la medida requiere atender a su finalidad y a sus efectos. En este sentido, y con relación a la igualdad en la Ley, el Tribunal Constitucional afirmó, muy tempranamente, que el trato normativo diferenciado del legislador vulnera el principio de igualdad "si la desigualdad está desprovista de una justificación objetiva y razonable, y la existencia de dicha justificación debe apreciarse en relación a la finalidad y efectos de la medida considerada, debiendo darse una relación razonable de proporcionalidad entre los medios empleados y la finalidad perseguida" (STC 22/1981, de 2 de julio, FJ $3^{\circ}$ ). La cursiva es añadida.

25 Sencillamente, esto no es cierto. La disposición adicional segunda de la Ley Orgánica para la igualdad efectiva de mujeres y hombres establece que en los procesos electorales al Congreso, Parlamento europeo, autonómicos y locales, la proporción mínima del cuarenta por ciento se mantendrá en cada tramo de cinco puestos (teniendo en cuenta que las mismas reglas serán de aplicación a las listas de suplentes). Señalar, otro lado, que la experiencia electoral provincial y municipal belga del año 1994 ya puso de manifiesto que la reserva de una cuota electoral para el sexo infrarrepresentado es una medida funcionalmente ineficaz si se excluye a sus candidatos de los lugares en los que existe posibilidades de elección; M. Verdussen, "La participation des femmes aux eléctions en Belgique", Revue Française de Droit Constitutionnel, núm. 36, 1998, págs. 799 y ss. Sobre esta misma cuestión véase M. MATEO DíAz, "Les quotas sont-il utiles? L'efficacité imparfaite des mesures de discrimination positiva dans les lois électorales belges", Revue Française de Droit Constitutionnel, núm. 53, 2003; J. GARCía AÑón, "Representación política de las mujeres y cuotas", Derechos y Libertades. Revista del Instituto Bartolomé de las Casas, núm. 11, enero-diciembre 2002, págs. 365-366.

26 Con dichas excepciones se trata de paliar las dificultades que puede suponer componer una lista respetuosa con los porcentajes legalmente exigidos en los núcleos de población reducidos. Se trata así de solventar el problema que puede ocasionar una concepción según la cual se da por supuesto que siempre habrá un número suficiente de mujeres dispuestas a figurar en las listas electorales cuando ello, especialmente en las poblaciones pequeñas, no siempre es así. Véase, al respecto, M. MARTínez SOSPEDRA, "La sombra de Agamenón. Sobre la constitucionalidad del establecimiento de la cuota por razón de sexo en las listas...", ob. cit., pág. 115. Por otra parte, la 
titucionales en tanto en cuanto no resulta lesiva para el ejercicio de derechos fundamentales. En este punto, el intérprete supremo de la Constitución señala que no se vulneran ni la libertad ideológica de los partidos políticos (artículo 16.1 CE) ni su libertad de expresión (artículo 20.1.a CE), porque los porcentajes establecidos por la norma no impiden a los sujetos legitimados para presentar candidaturas defender y expresar libremente sus tesis, incluso contrarias, sobre paridad electoral (en la contienda electoral, o una vez terminada ésta en los órganos en los que hubieran obtenido representación) ${ }^{27}$. Tampoco considera que se produzca una vulneración del derecho de asociación política del artículo 6 en conexión con el artículo 22.

Llama la atención, sin embargo, la débil y escasa justificación que utiliza el Alto Tribunal para negar que la medida discutida incida en el derecho de asociación (en su vertiente política) del artículo 22 de la Constitución. Según el fundamento jurídico quinto de su sentencia 12/2008, de 29 de enero ${ }^{28}$, el contenido del derecho de asociación del precepto mencionado se articula en torno a cuatro facetas o dimensiones: libertad de creación de asociaciones y de adscripción a las ya creadas, libertad de no asociarse y de dejar de pertenecer a las mismas, libertad de organización y funcionamiento internos sin injerencias públicas, y, como dimensión inter privatos, garantía de un haz de facultades a los asociados individualmente considerados frente a las asociaciones a las que pertenecen o a las que pretendan incorporarse. La reserva legal de porcentajes por razón de sexo en el momento de la composición de las candidaturas electorales no incide, en su opinión, en ninguna de estas cuatro dimensiones sino que, por el contrario, sólo se refiere a la libertad de actuación externa de los partidos y no a su vida interna ordinaria. Precisamente por ello, no puede existir vulneración alguna de la dimensión relativa a su libertad de organización y funcionamiento internos.

La consecuencia de la negación del conflicto entre el principio de igualdad en el acceso al cargo representativo y el derecho de asociación política en su vertiente organizativa interna se desprende inmediatamente: el Tribunal no tiene la necesidad de abordar la cuestión relativa a su ponderación ni, por consiguiente, de aplicar el parámetro argumentativo de la proporcionalidad en sentido amplio para resolver un conflicto que, a su juicio, es inexistente (podríamos añadir aquí que la justificación que emplea en la sentencia sobre la

profesora MARTín VIDA se ha referido a la flexibilidad como un requisito (en el que insiste especialmente el Tribunal de Justicia de las Comunidades Europeas cuando indaga sobre la compatibilidad de las medidas de discriminación inversa con el Derecho comunitario) que garantiza la existencia de un cierto margen que permite apreciar las circunstancias concurrentes en cada caso concreto y que hace posible adaptar la medida en su aplicación específica e irla haciendo evolucionar en el tiempo en función de la modificación de dichas circunstancias; Ma A. MARTín VIDA, Fundamentos y límites constitucionales de las medidas de acción..., ob. cit., pág. 229.

27 En el mismo sentido, señalando que la obligación de cumplir listas paritarias no significa que los partidos deban estar de acuerdo materialmente con la norma que establece dicho requisito y que no implica, por tanto, una renuncia a la propia ideología; O. SÁnchez Muñoz, $L a$ igualdad de oportunidades en las competiciones..., ob. cit., pág. 153.

28 Siguiendo, a su vez, lo dispuesto en el FJ $3^{\circ}$ de la STC 133/2006, de 27 de abril. 
proporcionalidad de la medida presenta una naturaleza fundamentalmente cuantitativa frente a la naturaleza cualitativa de una argumentación basada en el principio de proporcionalidad en sentido amplio).

En mi opinión, sin embargo, resulta altamente discutible sostener que la elaboración de las candidaturas electorales no se configura como una manifestación de la libertad de organización y funcionamiento interno de los partidos políticos; es más, estoy plenamente convencida de que la decisión sobre la composición de las listas electorales es una decisión propia de la organización y funcionamiento interno de los partidos y de que, por tanto, la reserva de porcentajes por razón de sexo en este ámbito afecta al derecho de asociación política ${ }^{29}$. Otra cosa es que dicha incidencia o afectación incurra o no en inconstitucionalidad, una cuestión esta última que sólo se puede resolver aplicando el parámetro argumentativo que proporciona el juicio de proporcionalidad en sentido amplio y que exige comprobar, primero, que la medida sirva o resulte eficaz para corregir la situación de desigualdad (juicio de idoneidad), segundo, que se utilice sólo cuando no exista otro medio más moderado para corregir con el mismo nivel de eficacia la infrarrepresentación de un sexo determinado (juicio de necesidad), y, tercero, que genere más beneficios para el interés general que perjuicios sobre otros bienes o valores en conflictos (juicio de proporcionalidad en sentido estricto).

Es cierto, por otra parte, que el juicio de proporcionalidad, al fin y al cabo un instrumento para fiscalizar las intervenciones que se traducen en una restricción de bienes o derechos constitucionales, presenta muchos más problemas dogmáticos cuando se utiliza para fundamentar el juicio sobre la validez constitucional de las leyes que limitan las normas de derechos fundamentales (en el caso presente, el derecho de asociación política), ya que, en efecto, en estos supuestos el control de proporcionalidad debe resolver la relación de tensión existente entre el legislador y el juez constitucional. Todos los subprincipios integrantes de la proporcionalidad en sentido amplio (idoneidad, necesidad y proporcionalidad en sentido estricto) se proyectan sobre una serie de decisiones con un alto contenido político y, desde este punto de vista, el principal peligro de su aplicación descansa en un abuso por parte del órgano judicial que decide introducir su propia apreciación subjetiva de la norma sustituyendo así el juicio político realizado por el legislador ${ }^{30}$. Precisamente para evitar esta situación, tanto el propio Tribunal Constitucional ${ }^{31}$,

29 En este sentido véase, igualmente, O. SÁnCHEz Muñoz, La igualdad de oportunidades en las competiciones..., ob. cit., págs. 153-154.

30 En este sentido véase Rubio Llorente, "La igualdad en la jurisprudencia del Tribunal Constitucional. Introducción", Revista Española de Derecho Constitucional, núm. 31, 1999, pág. 32; J. BARNÉs, "El principio de proporcionalidad. Estudio preliminar", Cuadernos de Derecho Público, núm. 5, septiembre-diciembre 1998, págs. 43-44; J. JimÉnEz CAMPO, "La igualdad jurídica como límite frente al legislador", Revista Española de Derecho Constitucional, núm. 9, 1983, pág. 78.

31 El FJ $6^{\circ}$ de la STC 66/1995, de 8 de mayo, ya señalaba que "La posición constitucional del legislador (...) obliga a que la aplicación del principio de proporcionalidad para controlar constitucionalmente sus decisiones deba tener lugar de forma y con intensidad cualitativamente 
como la doctrina que se ha dedicado al estudio de esta cuestión ${ }^{32}$, ponen el acento en la necesidad de actuar con una gran prudencia cuando se fiscaliza la proporcionalidad de la obra legislativa, de tal forma que la decisión sobre la desproporción de una medida normativa que limita bienes o derechos constitucionales sólo se alcance cuando se desborde la idoneidad, necesidad y proporcionalidad en sentido estricto de una "forma evidente y manifiesta, lo que implica, desde luego, que tan sólo la desproporción extrema y objetivable adquiera relevancia jurídica y que no sea ésta, por lo demás, una hipótesis frecuente ${ }^{33}$.

Ya he señalado, en otro trabajo ${ }^{34}$, que la reserva legal de porcentajes por razón de sexo en el momento de la composición de las candidaturas electorales supera las exigencias de idoneidad y necesidad del juicio de proporcionalidad en sentido amplio, ya que, por una parte, la medida contribuye o resulta adecuada para hacer realidad, en mayor o menor grado ${ }^{35}$, la igualdad real y efectiva en el acceso al cargo representativo por razón de sexo y, por otra, tampoco salta a la vista, de forma evidente y manifiesta, que exista una alternativa menos restrictiva o más moderada y que sea capaz de conseguir el objetivo pretendido con el mismo grado de eficacia ${ }^{36}$. La falta de razonabilidad

distinta [evidentemente menor] a las aplicadas a los órganos encargados de aplicar e interpretar las leyes. Como acabamos de recordar, este Tribunal ha reiterado que el legislador no se limita a ejecutar o aplicar la Constitución, sino que, dentro del marco que ésta traza, adopta libremente las opciones políticas que en cada momento estima más oportunas". Posteriormente, nuevas resoluciones del Tribunal Constitucional, las sentencias 161/1997, de 2 de octubre, y, mucho más recientemente, la 233/2004, de 7 de junio, vuelven a subrayar que el control basado en el principio de proporcionalidad en sentido amplio que puede realizar el Alto Tribunal sobre el legislador presenta un alcance limitado.

32 Sobre el principio de proporcionalidad pueden consultarse los trabajos de L. VillacorTA ManceBo, "Principio de igualdad y legislador: arbitrariedad y proporcionalidad como límites (probablemente insuficientes)", Revista de Estudios Políticos, núm. 130, octubre-diciembre 2005; M. GONZÁLEz BeILfuss, El principio de proporcionalidad en la jurisprudencia del Tribunal Constitucional, ed. Thomson/Aranzadi, Madrid 2003; J. BARNÉs, "El principio de proporcionalidad. Estudio preliminar" y M. MEDINA GuERRERO, "El principio de proporcionalidad y el legislador de los derechos fundamentales", ambos publicados en Cuadernos de Derecho Público, núm. 5, septiembrediciembre 1998.

33 J. BARnÉs, "El principio de proporcionalidad. Estudio...", ob. cit., pág. 16.

$34 \mathrm{M}^{\mathrm{a}}$ L. Martínez Alarcón, Cuota electoral de mujeres y Derecho Constitucional, ed. Congreso de los Diputados, Madrid 2007, págs. 204-211.

$35 \mathrm{El}$ incumplimiento del juicio de idoneidad sólo se produce cuando la medida prevista se revela como manifiestamente inútil para conseguir la finalidad pretendida y éste no es el caso. Ni este instrumento resulta manifiestamente inútil para conseguir la finalidad pretendida, ni puede ser descartado por no ser considerado el mecanismo más útil para conseguirla (es un instrumento útil para su consecución en alguna medida y con eso basta para superar el juicio de idoneidad).

36 Se habla de la existencia de medios alternativos frente al modelo de la cuota electoral que consistirían, básicamente, en medidas dirigidas a garantizar la igualdad de oportunidades para, a su través, provocar un incremento de la presencia de mujeres en los órganos representativo. Ahora bien, este tipo de medidas no parecen ofrecer el mismo grado de eficacia en la consecución del objetivo pretendido por el legislador (el incremento de la presencia de la mujer en los órganos representativos), que, al menos a corto plazo, garantiza la cuota electoral legal. Por este motivo, la medida supera el juicio de necesidad. 
de la instrumentación de la medida contenida en la disposición adicional segunda de la Ley Orgánica para la igualdad efectiva de mujeres y hombres no deriva, pues, ni de su falta de idoneidad ni de su falta de necesidad.

Más discutible resulta, sin embargo, que dicha medida se pueda justificar atendiendo al parámetro de la proporcionalidad en sentido estricto. Conforme al mismo, su constitucionalidad requiere la existencia de un balance favorable de los beneficios que procura frente a las afectaciones que impone. Sensu contrario, la medida es inconstitucional atendiendo a este parámetro cuando genera más perjuicios que beneficios en el conjunto de derechos o intereses que entran en conflicto. La técnica de la proporcionalidad en sentido estricto nos obliga, en definitiva, a confrontar las razones que se oponen a la restricción del derecho fundamental (en este caso la asociación política) con aquéllas que aduce el legislador a favor de su intervención (la igualdad sustancial por razón de sexo en el ámbito representativo) ${ }^{37}$ para decidir si se produce o no un sacrificio excesivo que acarree, de forma manifiesta (patente, evidente), más perjuicios para el interés general que ventajas o beneficios.

Los beneficios que procuraría una medida de estas características son dos fundamentalmente: la garantía de la igualdad material por razón de sexo en el acceso al cargo representativo y la ventaja relativa a la paulatina modificación del contrato social propio del Estado liberal (pues, en efecto, una presencia mínima de las mujeres en los órganos representativos permitiría superar su invisibilidad en la vida pública y repercutiría favorablemente en el proceso de cambio de unos hábitos sociales que todavía son consecuencia de un entendimiento asimétrico de las relaciones en función del sexo que, durante mucho tiempo, ha asignado tareas en función del sexo y que ha excluido a la mujer de la vida pública, subordinándola al varón en la vida privada) ${ }^{38}$. Estos beneficios son, ciertamente, muy importantes, tanto para el colectivo de mujeres como, más allá, para el conjunto de la sociedad en general. Sin embargo, las afectaciones que impone la medida en el derecho fundamental de asociación política y, a su través, en el valor del pluralismo político (elemento consustancial de nuestro Estado democrático) son tan relevantes que, en mi opinión, permiten concluir con la desproporción y consiguiente inconstitucionalidad de la medida (al menos, tal y como la describe la disposición adicional segunda de la Ley Orgánica para la igualdad efectiva de mujeres y hombres ${ }^{39}$ ).

37 R. AlEXY, Teoría de los Derechos Fundamentales (1986), trad. de E. Garzón Valdés, 2a reimpresión, CEPC, Madrid 2001, pág. 111 y ss.

38 Sobre este efecto colectivo de la medida véase, entre otras, B. RuIz RodRíGuEz y R. RuBIO MARín, "De paridad, igualdad y representación en el Estado...", ob. cit., págs. 137-139; Mª L. BALAGUER CALLEJÓN, "Desigualdad compensatoria en el acceso a cargos representativos en el ordenamiento jurídico español. Situaciones comparadas", Mujer y Constitución en España, CEPC, Madrid 2000, pág. 394.

39 Frente a ella, las leyes electorales que introducen cuotas electorales por razón de sexo de incentivos no plantean tantos problemas de índole constitucional habida cuenta la autonomía que dejan a las formaciones políticas para, asumiendo las consecuencias jurídicas derivadas del incumplimiento (por ejemplo en materia de subvenciones estatales o de cuota de pantalla en los medios de comunicación social), optar por asumirla o no en el momento de la composición de 
He señalado en otras ocasiones que la dimensión objetiva del artículo 6 de la Constitución (relativa a la garantía institucional del pluralismo político) ${ }^{40}$ condiciona la dimensión subjetiva de este mismo precepto ${ }^{41}$ porque limita la capacidad del legislador para disciplinar el derecho de partidos habida cuenta de que cualquier regulación sobre partidos políticos debe respetar su configuración como instrumentos básicos para hacer realidad el valor del pluralismo político ${ }^{42}$. Esto es, el legislador no puede regular los partidos políticos de forma que los haga irreconocibles en cuanto a los objetivos y contenidos a cuya satisfacción los destinó el legislador constituyente y, en todo caso, su capacidad para incidir en el ámbito de su libertad programática (Programmfreibeit), esto es, en su libertad para concretar — en el momento de su constitución, aunque también posteriormente- sus fines y objetivos y para organizarse de forma coherente con los mismos (por ejemplo, componiendo candidaturas electorales), debe ser entendida en términos sumamente restrictivos $^{43}$.

Pues bien, la imposición de los porcentajes que introduce la disposición adicional segunda de la Ley Orgánica para la igualdad efectiva de mujeres y hombres se acerca peligrosamente a lo que bien pudiéramos calificar como una actitud dirigista por parte del poder público, que busca la imposición de

sus candidaturas. En cualquier caso, también esta modalidad legal — más moderada - de cuota electoral por razón de género, precisa respetar ciertos niveles de proporcionalidad, pues, en efecto, una previsión legal en estos ámbitos demasiado restrictiva podría afectar al status de igualdad de oportunidades que también define la naturaleza jurídica de estas formaciones políticas, y que adquiere especial relevancia durante el desarrollo de los procesos electorales. Por su parte, el profesor SÁNCHEZ MuÑoz distingue entre las normas que imponen la presencia de una determinada proporción de candidatos de ambos sexos en las candidaturas — comúnmente llamadas "cuotas" y las normas que no imponen obligatoriamente una determinada proporción, pero que incentivan el logro del equilibrio mediante "premios" o "castigos" relacionados con la financiación pública o con la visibilidad a través de espacios gratuitos en los medios de comunicación públicos. Y se centra en las cuotas, porque éstas son las únicas normas que afectan a la libertad de presentación de las candidaturas, restringiendo la capacidad de los potenciales competidores para configurar las candidaturas de acuerdo con los criterios que consideren más oportunos; O. SánchEZ MuÑoz, La igualdad de oportunidades en las competiciones..., ob. cit., pág. 144.

40 Según la dimensión objetiva de este precepto "Los partidos expresan el pluralismo político, concurren a la formación y manifestación de la voluntad popular y son instrumento fundamental para la participación política".

41 La dimensión subjetiva de este precepto consiste en el derecho a la libre creación de partidos políticos dentro de la Constitución y la ley ("Su creación y el ejercicio de su actividad son libres dentro del respeto a la Constitución y a la ley").

42 R. L. Blanco Valdés, Los partidos políticos, ed. Tecnos, Madrid 1990, págs. 132-134; J. JIMÉNEZ CAMPO, "Sobre el régimen jurídico constitucional de los partidos políticos", Revista de Derecho Político, núm. 26, 1988, págs. 132-134. Recientemente se ha hablado del "principio de constitucionalización" y del "principio de constitucionalidad", que se identificarían, respectivamente, con las dos dimensiones (objetiva y subjetiva) que distinguió en su día el profesor JimÉNEz CAMPO en el contenido del artículo 6 de la Constitución; D. BAuTisTa Plaza, La función constitucional de los partidos políticos, ed. Comares, Granada 2006, pág. 14;

43 Sobre la restricción en las posibilidades de intervención en los partidos políticos véase J. J. Marco Marco, "El pluralismo político y sus límites: la ley de partidos políticos", Pluralismo. Perspectivas políticas y desarrollos normativos, AA.VV., ed. Tirant lo Blanch, Valencia 2004, pág. 257. 
una opinión dominante durante los procesos de constitución del poder constituido legislativo y que, en esencia, resulta incompatible con el reconocimiento de un Estado democrático (por definición, plural).

$Y$ es que, aunque es cierto, como afirma el Tribunal Constitucional, que los porcentajes establecidos por la norma no impiden a los sujetos legitimados para presentar candidaturas defender libremente sus tesis sobre paridad electoral o sobre cualquier otra cuestión (en la contienda electoral, o una vez terminada ésta en los órganos en los que obtienen representación), también lo es que la imposición de dichos porcentajes sin margen de decisión alguna (pues la formación política incumplidora queda excluida del proceso electoral), obliga a determinados partidos políticos a organizarse de forma incongruente con su propia identidad programática durante los procesos de constitución del poder constituido legislativo, y que, incluso, puede llegar a perjudicar gravemente a ciertas asociaciones políticas que defienden una ideología absolutamente contraria al establecimiento de cuotas a favor de la mujer en el ámbito representativo ${ }^{44}$. Primero porque el respeto necesario de la cuota, si quieren participar o tener la oportunidad de participar en el proceso de discusión y decisión política, acarrea serias dificultades para hacer llegar su discurso a la calle y convencer al ciudadano y a sus propios afiliados, a los que resulta difícil explicar cómo un partido político con unos concretos fines y objetivos compone determinadas listas electorales (aunque sean consecuencia de la imposición de un acto del poder público). Y segundo, y esto ya es más grave, porque defender cierto tipo de ideologías, muy alejadas de lo que parece ser la opinión dominante al respecto en España, puede impedir componer una candidatura como la que exige nuestro legislador orgánico y, consecuentemente, participar en la contienda electoral ${ }^{45}$. Desde este punto de vista, resulta posible afirmar que la medida pone en cuestión la función social del derecho de asociación política privándolo de su significación constitutiva para el orden constitucional y precisamente por ello considero que esta modalidad de leyes de paridad electoral, radical en cuanto a sus consecuencias, resulta excesiva, no proporcional.

En definitiva, y en mi opinión, cuando se obliga a un partido a adoptar decisiones incompatibles con su identidad programática o cuando alguna formación política puede quedar excluida del proceso electoral como consecuencia de la imposibilidad de respetar una cuota (lo que impediría a sus electores pronunciarse sobre la misma afectando a la propia libertad ideoló-

44 Me estoy refiriendo a formaciones políticas que, por ejemplo, pretendiendo mantener el concepto de familia propio de la tradición judeocristiana, consideran que no resulta negativo continuar manteniendo el reparto de roles tradicionalmente existente en la sociedad entre el hombre — esfera de lo público_ y la mujer — esfera de lo privado-; o a formaciones políticas con una ideología feminista o machista extrema.

45 Sobre la aplicación de la medida dispuesta en la Ley Orgánica para la igualdad efectiva de mujeres y hombres en las elecciones municipales y autonómicas celebradas en España el día 27 de mayo de 2007, véase J. L. García Guerrero, Escritos sobre Partidos Políticos. (Cómo mejorar la democracia), ed. Tirant lo Blanch, Valencia 2007, pág. 190. 
gica del cuerpo electoral), se produce un sacrificio desproporcionado. Máxime en un contexto como el español en el que el sistema de partidos no resulta especialmente sospechoso — si nos fijamos en lo que venía acaeciendo en los momentos previos a la introducción de esta Ley- de olvidar el tema de la promoción de la mujer en el ámbito político representativo. En España, como en otros países, importantes partidos políticos están comprometidos con medidas como la cuota electoral y, precisamente, ha sido la incorporación voluntaria de una cuota electoral por parte de algunos partidos políticos a sus disposiciones estatutarias lo que ha generado un efecto "bola de nieve" en el resto de partidos, que han tomado conciencia - estén o no a favor del sistema de cuotas- de que la selección o designación de mujeres para componer sus listas electorales acarrea réditos electorales considerables ${ }^{46}$.

\section{III.2. LA OBJECIÓN RELATIVA A LA SUPUESTA VULNERACIÓN DEL PRINCIPIO DE LA REPRESENTACIÓN POLÍTICA.}

No podría terminar este comentario sin referirme a la objeción que soporta la medida sobre su supuesta vulneración del principio de la representación política y que el Tribunal Constitucional resuelve de una forma breve en el último fundamento jurídico de la sentencia 12/2008, de 29 de enero (posiblemente porque considera —en mi opinión de forma acertada- que el principal problema constitucional de fondo que plantea la reserva legal de porcentajes por razón de sexo en el momento de la composición de las candidaturas electorales es el relativo a su incidencia en el derecho de partidos). Para el intérprete supremo de la Constitución, la disposición adicional segunda de la Ley Orgánica para la igualdad efectiva de mujeres y hombres no conduce a una fragmentación del cuerpo electoral; no quiebra la unidad de la categoría de ciudadano a través de una compartimentación del cuerpo electoral en función del sexo que cree vínculos especiales entre electores y elegibles. Tampoco entraña un riesgo cierto de disolución del interés general en un conjunto de intereses parciales o por categorías (ya que los electos, aunque lo hayan sido gracias a la aplicación de los porcentajes, representarán al electorado en su conjunto y no sólo a los electores de su mismo sexo $)^{47}$.

46 Véase, en este sentido, P. Biglino Campos, "Las mujeres en los partidos políticos", Mujer y Constitución en España, coord. Teresa Freixes SAnjuan, CEC, Madrid 2000, pág. 427.

47 Sosteniendo una opinión contraria a la constitucionalidad de la medida por su supuesta vulneración del principio de la representación política tal y como está recogido en nuestro texto constitucional véase el voto particular formulado por el Magistrado D. Jorge Rodríguez-Zapata Pérez a la STC 12/2008, de 29 de enero. Téngase en cuenta que esta objeción se planteó por primera vez en el vecino país galo cuando el Conseil Constitutionnel francés frustró la promulgación de un Proyecto de Ley de reforma de las elecciones municipales que prevenía que las listas de candidatos no podían contener más del 75\% de personas del mismo sexo (Decisión n. 82-146 DC, de 18 de noviembre de 1982). FAVOREAu, desarrollando los argumentos del Consejo, afirma que sólo en países como Bélgica, donde la propia Constitución no reconoce la unidad del cuerpo electoral al garantizar la presencia de un número igual de miembros de la comunidad valona y 
A mi juicio (y también muy brevemente), un análisis correcto de este problema de constitucionalidad pasa necesariamente por diferenciar dos entendimientos completamente diferentes de la cuota electoral legal y que conducen a conclusiones diversas.

Así, la reserva de porcentajes electorales en el momento de la composición de las candidaturas electorales, entendida - como es mi caso- como un instrumento provisional destinado a dar satisfacción al principio de igualdad sustancial en el acceso al cargo representativo, no quiebra el concepto de representación política que estableció nuestro constituyente sustituyéndolo por un modelo de representación de intereses de categoría. Bajo el prisma de la cuota electoral legal temporal la función representativa continúa correspondiendo a los ciudadanos individualmente considerados (aún cuando el sexo pueda haber sido un elemento que haya condicionado su inclusión en listas electorales). No se produce, en este contexto, ni una división del pueblo en dos mitades (el pueblo-hombres y el pueblo-mujeres), ni una escisión del cuerpo electoral en categorías, de tal forma que la mujer y el varón se conviertan en compartimentos estancos que voten sólo a representantes de su mismo sexo que, a su vez, aparezcan destinados a defender los intereses de su grupo olvidándose de esta forma de la defensa del interés general referido a todos los ciudadanos. Las mujeres que acceden a los puestos de representación política gracias a la aplicación de la cuota electoral no se eligen sólo por mujeres y, además, se eligen para participar en el proceso de construcción del interés general ${ }^{48}$. Desde este punto de vista, no puedo sino compar-

flamenca en el seno del Consejo de Ministros, sería posible un sistema de cuotas de mujeres impuesto por el Estado para cubrir los cargos representativos. En los que mantienen la unidad del cuerpo electoral, como en Francia, esto sería imposible, salvo que se reformara previamente la Constitución (como finalmente se ha hecho) para permitirlas, si bien, y a pesar de eso, al autor prefiere, frente a la reforma constitucional, respetar la autonomía de los partidos políticos para que sean ellos los que decidan sobre el establecimiento o no de cuotas; L. Favoreau, "Principio de igualdad y representación política de las mujeres. Cuota, paridad y Constitución", Revista Española de Derecho Constitucional, núm. 50, mayo-agosto 1997, págs. 22-24. Otros autores que se mostraron contrarios a la reserva legal de porcentajes en el ámbito de la composición de las candidaturas electorales por parecidos motivos han sido, en la doctrina italiana, G. BRUNELLI, en "L'alterazione del concetto de rappresentanza politica: leggi elettorali e "quote" riservate alla donne", Diritto e Società, 3, 1994, pág. 545 y ss., y en "Azioni positive in materia elettorale?", $R a$ gion Pratica, núm. 4, 1995, pág. 586; G. LuchenA, "Le azioni positive nelle recenti riforme costituzionali: il difficile equilibrio tra misure preferenziale e tutela delle posizioni soggettivve dei terZi”, Rassegna Parlamentare, 2, 2003, pág. 445; y en la doctrina española, A. Elvira, en "Representación y sexo", Debates Constitucionales. Revista Electrónica Derecons, núm. 1, julio de 1999, pág. 9, y en "La participación política de la...", ob. cit., págs. 442-444; M. CARrillo, "Cuotas e igualdad por razón de sexo: una reforma constitucional", Estudios de Derecho Constitucional. Homenaje al profesor dr. D. Joaquín García Morillo, ed. Tirant lo Blanch, Valencia 2001, págs. 162-172; E. ARANDA Álvarez, Cuota de mujeres y régimen electoral, Cuadernos "Bartolomé de las Casas", ed. Dykinson, Madrid 2001.

48 En parecidos términos véase P. Biglino Campos, "Las mujeres en los partidos...", ob. cit., pág. 414; J. Sevilla Merino, Mujeres y ciudadania: la democracia..., ob. cit., págs. 48-49; M. GuRRERA ROIG, "Veinticinco años de paridad hombre-mujer", Revista de Derecho Político, núms. 58-59, 2003, págs. 145-148; F. Aguiar, "A favor de las cuotas...", ob. cit., págs. 30-31; E. Martínez Sempe- 
tir la opinión sostenida por la sentencia del Tribunal Constitucional 12/2008, de 29 de enero al respecto y discrepar con la principal objeción que formula a la medida el Magistrado D. Jorge Rodríguez Zapata-Pérez en el voto particular.

Una conclusión diferente, sin embargo, se desprende cuando la medida se plantea entendida en términos definitivos; como un fin en sí misma considerada, con vocación de permanencia en el tiempo y no, por tanto, como un instrumento provisional o temporal para hacer frente a una situación de desigualdad sustancial por razón de sexo en el ámbito representativo que debe desaparecer cuando desaparezca esa desigualdad sustancial de hecho a la que pretendió dar en su día respuesta. Un entendimiento éste que se desprende, por otra parte, de la tesis - que no comparto- de que hombres y mujeres no son intercambiables durante el proceso de la representación política y de que, por tanto, cada uno de ellos resolverá de forma diferente y en atención a los intereses de su grupo social de pertenencia. En mi opinión, esta justificación y comprensión de la medida dispuesta en la Ley Orgánica para la igualdad efectiva de mujeres y hombres, que responde, a su vez, a una comprensión corporativa de la función representativa por razón de sexo, resulta ajena al modelo vigente del principio de la representación política que desarrolla nuestro texto constitucional y exigiría, en su caso, una reforma previa del mismo.

ABSTRACT.- The second additional disposition of the Organic Law for effective equality of women and men establishes certain percentages based on sex during the composition of the electoral candidacies and the judgment of the Constitutional Court 12/2008, of January 29, has confirmed its constitutionality. In my opinion, nevertheless, some points of this decision of the Constitutional Court are debatable: the nature ot the measure but, above all, the lack of rationality of its effects in relation with the fundamental right of association.

RE, "La legitimidad de la democracia paritaria", Revista de Estudios Políticos, núm. 107, enero-marzo 2000, págs. 145-148; A. Rodríguez-Vergara Díaz, "Reflexiones constitucionales sobre la paridad electoral. Artículo 14", Boletín de Información y análisis jurídico, Instituto Andaluz de la Mujer, núm. 2, septiembre 1999, pág. 4. 